Article

\title{
Impact of Sample Size and Maximum Aggregate Grain on the Representativeness of Concrete Samples
}

\author{
Jacek Śliwiński * and Patrycja Duży \\ Faculty of Civil Engineering, Chair of Building Materials Engineering, Cracow University of Technology, \\ 31-155 Cracow, Poland; patrycja.duzy@interia.pl \\ * Correspondence: jacek.sliwinski@pk.edu.pl
}

Received: 28 May 2020; Accepted: 28 June 2020; Published: 1 July 2020

\begin{abstract}
One of the basic criteria for the representativeness of composite material samples is the similarity of the quantitative and qualitative composition of the material in the sample to that of the material it represents. The article presents the results of experimental research concerning the impact of the ratio of the minimum size of cubic concrete samples $\left(l_{\min }\right)$ to the maximum size of aggregate grain $\left(D_{\max }\right)$. The content of the basic components of concrete, i.e., coarse aggregate, mortar, sand and cement paste, was analysed. The content of these components in the concrete sample was identified by means of analysis of the sample cross-sectional image, and then, compared with the contents resulting from the concrete mixture proportion. Cases where $1_{\min } / \mathrm{D}_{\max }$ was between 2.38 and 12.5 were analysed. The results of the study indicate a moderate correlation between these two parameters. The largest discrepancies between the component contents of the sample and the controlled concrete were usually recorded at the extreme values of the $1_{\min } / \mathrm{D}_{\max }$ ratio. These discrepancies, depending on the component in question, range from approx. -15 to approx. $+15 \%$. Acceptable deviations $(\leq \pm 5 \%)$ result in the value of this ratio within the estimated range between approximately 5.0 and approximately 10.0. In existing standards, the use of samples that meet the requirement $l_{\min } / \mathrm{D}_{\max } \geq 3.0$ or 3.5 is recommended. In light of the presented test results, this requirement is sufficient for the material properties that are not sensitive to slight variation in concrete composition, i.e., compressive and tensile strength. The presented results are useful in the case of sample size selection for the study of concrete properties which are most sensitive to concrete composition changes. These properties include water absorption, permeability to liquids and gases, thermal properties, etc.
\end{abstract}

Keywords: concrete; samples; composition; representativeness

\section{Introduction}

Cement concrete is one of the typical heterogeneous, multi-component building materials. Regardless of the concrete variety (ordinary, high performance, self-consolidating, etc.), this material can be classified to a group of granular composites, consisting of a mineral matrix and a mineral granular inclusion in the form of solid grains of different sizes. In the case of structural concretes, the matrix is formed by hardened cement paste and the inclusion of stone aggregate grains with the size from 0 to $D_{\max }$. In such concretes, $D_{\max }$ does not exceed $63 \mathrm{~mm}$. Aggregate with $D_{\max }=16 \mathrm{~mm}$ is most commonly used. It should be added that the aggregate consists of fine aggregate grains (sand from 0 to $2 \mathrm{~mm}$ ) and coarse aggregate grains (gravel or crushed aggregate), with grains from $2 \mathrm{~mm}$ to $\mathrm{D}_{\max }$.

In general, in typical ordinary concrete, the volume content of hardened paste is approx. $300 \mathrm{dm}^{3} / \mathrm{m}^{3}$ and of the aggregate grains, approx. $700 \mathrm{dm}^{3} / \mathrm{m}^{3}$. As a result of physical and chemical processes taking place in the concrete mix, and then, in the curing concrete, part of the cement paste in the immediate vicinity of the aggregate grain surface undergoes some, most often unfavourable, 
modifications. As a result, the so-called Interfacial Transition Zone (ITZ) is created in the surroundings of aggregate grains, which significantly affects the properties of concrete. Assuming that the thickness of this zone is about 10 to $50 \mu \mathrm{m}$ [1] and that the aggregate has a typical, correct grain size, the content of modified paste in this zone can be estimated at a few percent of the total paste present in the concrete.

Even such a general description of cement concrete as a composite material clearly shows how heterogeneous it is. This is schematically presented in Figure 1.

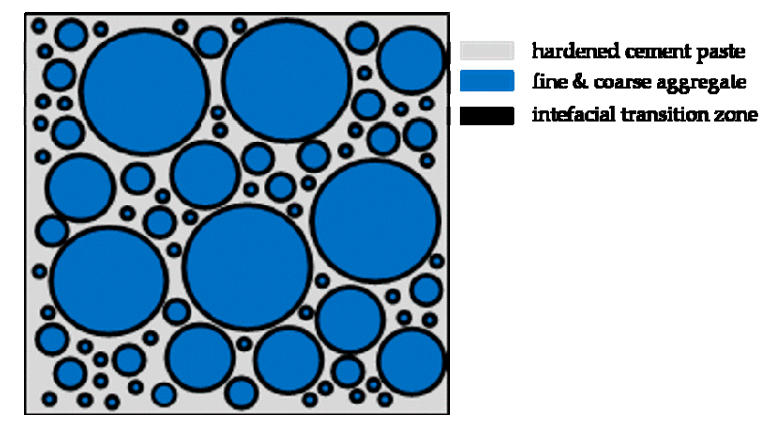

Figure 1. Schematic representation of cement concrete as a heterogeneous composite material consisting of hardened cement paste with fine and coarse aggregate grains.

In the case of a sample used in the study of any concrete properties, it must be representative of the studied population. A representative sample is one which, for a particular set of variables, represents a population, including its diversity [2]. Concrete samples should therefore be treated as a kind of "miniature" of the controlled concrete used for the construction. In the case of heterogeneous materials, samples for experimental evaluation of their properties should therefore have a volume at least equal to the so-called Representative Volume Element (RVE). A different, but similar in essence, definition of RVE states that it is the smallest volume on which a measurement can be made, which will give a value representative of the material being evaluated [3]. Thus, RVE is considered to mean a volume which represents a composite statistically, i.e., a volume in which all components of the material are included and in the same proportions as they occur in the represented material.

In a further part, the article contains the results of tests to answer the question of whether the ratio of minimum sample size $\left(l_{\min }\right)$ to maximum aggregate grain $\left(D_{\max }\right)$ affects the actual concrete composition in the sample and how much this composition may differ from the controlled concrete composition resulting from its formulation. The volumetric content of the basic concrete components, i.e., coarse aggregate with grains from $2 \mathrm{~mm}$ to $\mathrm{D}_{\text {max }}$, fine aggregate (sand) with grains up to $2 \mathrm{~mm}$ and hardened cement paste, was analysed. Known contents of paste and sand also allow to determine the mortar content. The study involved $40 \times 40 \times 160 \mathrm{~mm}$ prisms and cubic samples with the side dimension of 100, 150, 200 and $250 \mathrm{~mm}$ made of aggregate concrete with different maximum grain size $\left(D_{\max }\right)$. The use of different sample sizes $\left(l_{\min }\right)$ made of concrete with different maximum aggregate size $\left(D_{\max }\right)$ enabled the differentiation of the $l_{\min } / \mathrm{D}_{\max }$ ratio within the wide limits from 2.38 to 12.5 .

The main objective of the study was to assess the effect of this ratio on the actual concrete composition in the sample and to assess to what degree this composition is identical compared to the composition of the entire controlled concrete. Such information may be useful for the evaluation and interpretation of the results of tests on the properties of concrete particularly sensitive to the variability of concrete composition in the sample. Such properties include e.g., absorbability [4], permeability to liquids and gases [5] and thermal properties [6,7]. Excessive discrepancies between the concrete composition in the sample and in the controlled concrete may result in the assessment of these properties not being fully representative.

The article does not address issues related to other factors that may affect the correctness of the assessment of concrete properties on the basis of sample testing. The problem of the relationship between the results obtained during the testing of samples of different shapes was also omitted here, as well as the problem of using samples drilled out from an existing structure. 


\section{Standard Criteria for Representativeness of Concrete Samples}

The literature review shows that there are numerous and different approaches to the problem of assessing the representativeness of concrete-like composite samples. The most numerous are papers concerning the issue of representativeness in numerical modelling of the properties of heterogeneous materials [8-11]. Papers devoted to the representativeness of samples used in experimental studies of various properties of composite materials with cement matrix are much less numerous [12-14]. The reason for this is probably the fact that the general principles of sample size selection have been included in concrete testing standards for many years and have been successfully implemented. In most of the standards, the basic practical criterion for the representativeness of samples for testing the concrete properties is the ratio of the minimum sample cross-section size $\left(l_{\min }\right)$ to the maximum aggregate grain size $\left(D_{\max }\right)[15-17]$.

Different standards give different recommendations in this respect. EN 12390-1:2013 [16] specifies that a sample of any shape (cube, cylinder, prism) shall have a minimum cross-section size of $1_{\min } \geq 3.5 \mathrm{D}_{\max }$. ASTM C 192/C 192M [17] refers to the requirement $1_{\min } \geq 3 \mathrm{D}_{\max }$. EN 206:2014 [18] takes a sample with a side dimension of at least $150 \mathrm{~mm}$ as the basic cubic sample, while at the maximum grain size of $D_{\max }=16 \mathrm{~mm}$, it recommends using samples with a side dimension of at least $100 \mathrm{~mm}$ $\left(l_{\min } / D_{\max }=6.25\right)$, for $D_{\max }=31.5 \mathrm{~m}$-sample with a size dimension of at least $150 \mathrm{~mm}\left(1_{\min } / \mathrm{D}_{\max }=4.76\right)$ and for $D_{\max }=63 \mathrm{~mm}$-sample with a size dimension of at least $250 \mathrm{~mm}\left(1_{\min } / \mathrm{D}_{\max }=3.96\right)$.

\section{Materials, Test Samples and Methods}

\subsection{Materials}

Four concrete mixes with a composition typical for concretes commonly in practice were used in the study. These mixes only differed in the maximum grain size of the coarse aggregate $\left(D_{\max }=8\right.$, 16, 31.5 and $63 \mathrm{~mm}$ ). The concrete was made of CEM I $42.5 \mathrm{~N}$ Portland cement, tap water, $0 / 2 \mathrm{~mm}$ river sand, basalt grits of size groups $2 / 8,8 / 16,16 / 31.5$ and 31.5/63 mm and a polycarboxylate-based superplasticiser. The water to cement ratio $(\mathrm{w} / \mathrm{c})$ was 0.50 . Aggregates for concrete were composed in such a way that their screening curves were within the areas of correct grain size. In order to contrast the colour of the paste and sand grains, an admixture of red mineral pigment was used in the concrete composition. Detailed concrete mix compositions are presented in Table 1.

Table 1. Composition of concrete mixes by volume and weight.

\begin{tabular}{|c|c|c|c|c|}
\hline \multirow{2}{*}{ Component } & \multicolumn{4}{|c|}{ Concrete Aggregate with Maximum Grain Size: } \\
\hline & $D_{\max }=8 \mathrm{~mm}$ & $D_{\max }=16 \mathrm{~mm}$ & $\mathrm{D}_{\max }=31.5 \mathrm{~mm}$ & $D_{\max }=63 \mathrm{~mm}$ \\
\hline CEM 42.5 cement & \multicolumn{4}{|c|}{$365 \mathrm{~kg} / \mathrm{m}^{3}\left(118 \mathrm{dm}^{3} / \mathrm{m}^{3}\right)$} \\
\hline Water & \multicolumn{4}{|c|}{$182 \mathrm{~kg} / \mathrm{m}^{3}\left(182 \mathrm{dm}^{3} / \mathrm{m}^{3}\right)$} \\
\hline Fine aggregate (river sand $0 / 2 \mathrm{~mm}$ ) & \multicolumn{4}{|c|}{$662 \mathrm{~kg} / \mathrm{m}^{3}\left(250 \mathrm{dm}^{3} / \mathrm{m}^{3}\right)$} \\
\hline Coarse aggregate (basalt grits $2 \mathrm{~mm} / \mathrm{D}_{\max }$ & \multicolumn{4}{|c|}{$1350 \mathrm{~kg} / \mathrm{m}^{3}\left(450 \mathrm{dm}^{3} / \mathrm{m}^{3}\right)$} \\
\hline Superplasticiser & \multirow{2}{*}{\multicolumn{4}{|c|}{$\begin{array}{l}1.0-1.5 \% \text { cement weight (not included in the volume balance) } \\
5 \% \text { cement weight (not included in the volume balance) }\end{array}$}} \\
\hline Pigment & & & & \\
\hline $\mathrm{w} / \mathrm{c}$ ratio & \multicolumn{4}{|c|}{0.50} \\
\hline Paste content & \multicolumn{4}{|c|}{$300 \mathrm{dm}^{3} / \mathrm{m}^{3}$} \\
\hline Mortar content & \multicolumn{4}{|c|}{$550 \mathrm{dm}^{3} / \mathrm{m}^{3}$} \\
\hline
\end{tabular}

Densities used to determine the volumetric content of each component: cement $\rho_{\mathrm{c}}=3.1 \mathrm{~g} / \mathrm{cm}^{3}$, water $\rho_{\mathrm{w}}=1.0 \mathrm{~g} / \mathrm{cm}^{3}$, sand $\rho_{\mathrm{p}}=2.6 \mathrm{~g} / \mathrm{cm}^{3}$, basalt grits $\rho_{\mathrm{b}}=3.0 \mathrm{~g} / \mathrm{cm}^{3}$.

The constant parameters of the composition were the content of cement, water, sand (and therefore, also the content of paste and mortar), coarse aggregate and pigment. The content of the superplasticiser varied from 1 to $1.5 \%$ of the cement weight. It was dosed in order to obtain a similar consistency for all mixtures (slump test-approx. $100 \mathrm{~mm}$ ). Due to very small amounts of superplasticiser and 
pigment, these components were not included in the volume balance calculations. Table 2 shows the composition of coarse aggregates with different $D_{\max }$ values.

Table 2. Content of different grain sizes in coarse aggregates with different maximum grain $\mathrm{D}_{\max }$.

\begin{tabular}{|c|c|c|c|c|}
\hline \multirow{2}{*}{ Components of Coarse Aggregate } & \multicolumn{4}{|c|}{ Aggregate with Maximum Grain Size: } \\
\hline & $D_{\max }=8 \mathrm{~mm}$ & $D_{\max }=16 \mathrm{~mm}$ & $\mathrm{D}_{\max }=31.5 \mathrm{~mm}$ & $D_{\max }=63 \mathrm{~mm}$ \\
\hline Basalt grits $2 / 8 \mathrm{~mm}$ & $\begin{array}{c}1350 \mathrm{~kg} / \mathrm{m}^{3} \\
\left(450 \mathrm{dm}^{3} / \mathrm{m}^{3}\right)\end{array}$ & $\begin{array}{c}745 \mathrm{~kg} / \mathrm{m}^{3} \\
\left(248 \mathrm{dm}^{3} / \mathrm{m}^{3}\right)\end{array}$ & $\begin{array}{c}443 \mathrm{~kg} / \mathrm{m}^{3} \\
\left(148 \mathrm{dm}^{3} / \mathrm{m}^{3}\right)\end{array}$ & $\begin{array}{c}242 \mathrm{~kg} / \mathrm{m}^{3} \\
\left(81 \mathrm{dm}^{3} / \mathrm{m}^{3}\right)\end{array}$ \\
\hline Basalt grits $8 / 16 \mathrm{~mm}$ & - & $\begin{array}{c}605 \mathrm{~kg} / \mathrm{m}^{3} \\
\left(202 \mathrm{dm}^{3} / \mathrm{m}^{3}\right) \\
\end{array}$ & $\begin{array}{c}303 \mathrm{~kg} / \mathrm{m}^{3} \\
\left(101 \mathrm{dm}^{3} / \mathrm{m}^{3}\right)\end{array}$ & $\begin{array}{c}302 \mathrm{~kg} / \mathrm{m}^{3} \\
\left(101 \mathrm{dm}^{3} / \mathrm{m}^{3}\right)\end{array}$ \\
\hline Basalt grits 16/31.5 mm & - & - & $\begin{array}{c}604 \mathrm{~kg} / \mathrm{m}^{3} \\
\left(201 \mathrm{dm}^{3} / \mathrm{m}^{3}\right)\end{array}$ & $\begin{array}{c}403 \mathrm{~kg} / \mathrm{m}^{3} \\
\left(134 \mathrm{dm}^{3} / \mathrm{m}^{3}\right)\end{array}$ \\
\hline Basalt grits $31.5 / 63 \mathrm{~mm}$ & - & - & - & $\begin{array}{c}403 \mathrm{~kg} / \mathrm{m}^{3} \\
\left(134 \mathrm{dm}^{3} / \mathrm{m}^{3}\right)\end{array}$ \\
\hline
\end{tabular}

\subsection{Test Samples}

Concrete mixes were made in a typical laboratory mixer with a capacity of $100 \mathrm{dm}^{3}$. In order to ensure correct homogenisation of the components, the volume of the batch was set at $50 \mathrm{dm}^{3}$ for each test. The samples were made in steel moulds. The moulds were filled, and the mixture compacted in accordance with EN-12390-2:2019 [19].

The compositions in Table 1 are used to make samples of different sizes, which are described in Table 3. The minimum cross-section size of the sample $\left(l_{\min }\right)$, maximum size of aggregate grains $\left(D_{\max }\right)$ in the concretes from which they were made and the $l_{\min } / D_{\max }$ ratio are provided there. This ratio, as already mentioned, varied between 2.38 and 12.5. Some of the samples met and some of the samples intentionally did not meet the $1_{\min } / \mathrm{D}_{\max } \geq 3.5$ criterion mentioned above. Due to the extensive scope of the experimental program, each combination of sample size and maximum grain $\left(l_{\min } / \mathrm{D}_{\max }\right)$ was represented by only three samples. Undoubtedly, limiting the number of tested samples affected the reliability of the results. However, it seems that this sample number was sufficient to establish perceived trends.

Table 3. Sizes of analysed samples, maximum aggregate grain size $D_{\max }$ and $l_{\min } / D_{\max }$ ratio.

\begin{tabular}{|c|c|c|c|c|}
\hline Sample & Sample Dimensions [mm] & Minimum Size $1_{\min }[\mathrm{mm}]$ & Maximum Grain Size $D_{\max }[\mathrm{mm}]$ & $1_{\min } / D_{\max }$ \\
\hline \multirow{2}{*}{ prism } & \multirow{2}{*}{$40 \times 40 \times 160$} & \multirow{2}{*}{40} & 8 & 5 \\
\hline & & & 16 & 2.5 \\
\hline \multirow{9}{*}{ cubes } & \multirow{3}{*}{$100 \times 100 \times 100$} & \multirow{3}{*}{100} & 8 & 12.5 \\
\hline & & & 16 & 6.25 \\
\hline & & & 31.5 & 3.17 \\
\hline & \multirow{3}{*}{$150 \times 150 \times 150$} & \multirow{3}{*}{150} & 16 & 9.37 \\
\hline & & & 31.5 & 4.76 \\
\hline & & & 63 & 2.38 \\
\hline & \multirow{2}{*}{$200 \times 200 \times 200$} & \multirow{2}{*}{200} & 31.5 & 6.35 \\
\hline & & & 63 & 3.17 \\
\hline & $250 \times 250 \times 250$ & 250 & 63 & 3.96 \\
\hline
\end{tabular}

Samples were cured under standard laboratory conditions for 28 days. Then, a single slice with a thickness of approximately $3 \mathrm{D}_{\max }$ was cut out of each sample, from its central part. The cuts were made in a plane perpendicular to the smoothed surface of the samples and provided perfectly flat cross-sections. Three slices of each series of samples were further tested. 


\subsection{Methods}

The evaluation of the volumetric content of the components in the samples (hardened cement paste, fine aggregate (sand) with grains up to $2 \mathrm{~mm}$, coarse aggregate with grains from $2 \mathrm{~mm}$ to $D_{\max }$ and hardened mortar) was carried out on the basis of the analysis of images of the cross-sections of the samples. The few air pores were classified as a component of the cement paste. Still, according to the generalised Cavalieri principle [20,21], it was assumed that the content of the volume occupied by individual components in the sample (3D) is the same as their content found during observation of their cross-sectional area (2D).

\subsubsection{Preparing the Cross-Sectional Images of Samples}

The cross-sectional images of the samples were obtained with a standard scanner using a resolution of $72 \times 720$ dpi. Each of the three cut slices representing a given sample variant $\left(l_{\min } / D_{\max }\right)$ was scanned from one randomly selected side. Figures 2 and 3 show typical cross-sectional images of samples meeting and not meeting the $1_{\min } / \mathrm{D}_{\max }>3.5$. criterion. The upper edge of the image is the smoothed surface of the sample. In all cases, homogeneous distribution of aggregate grains was observed. No signs of component segregation were found.
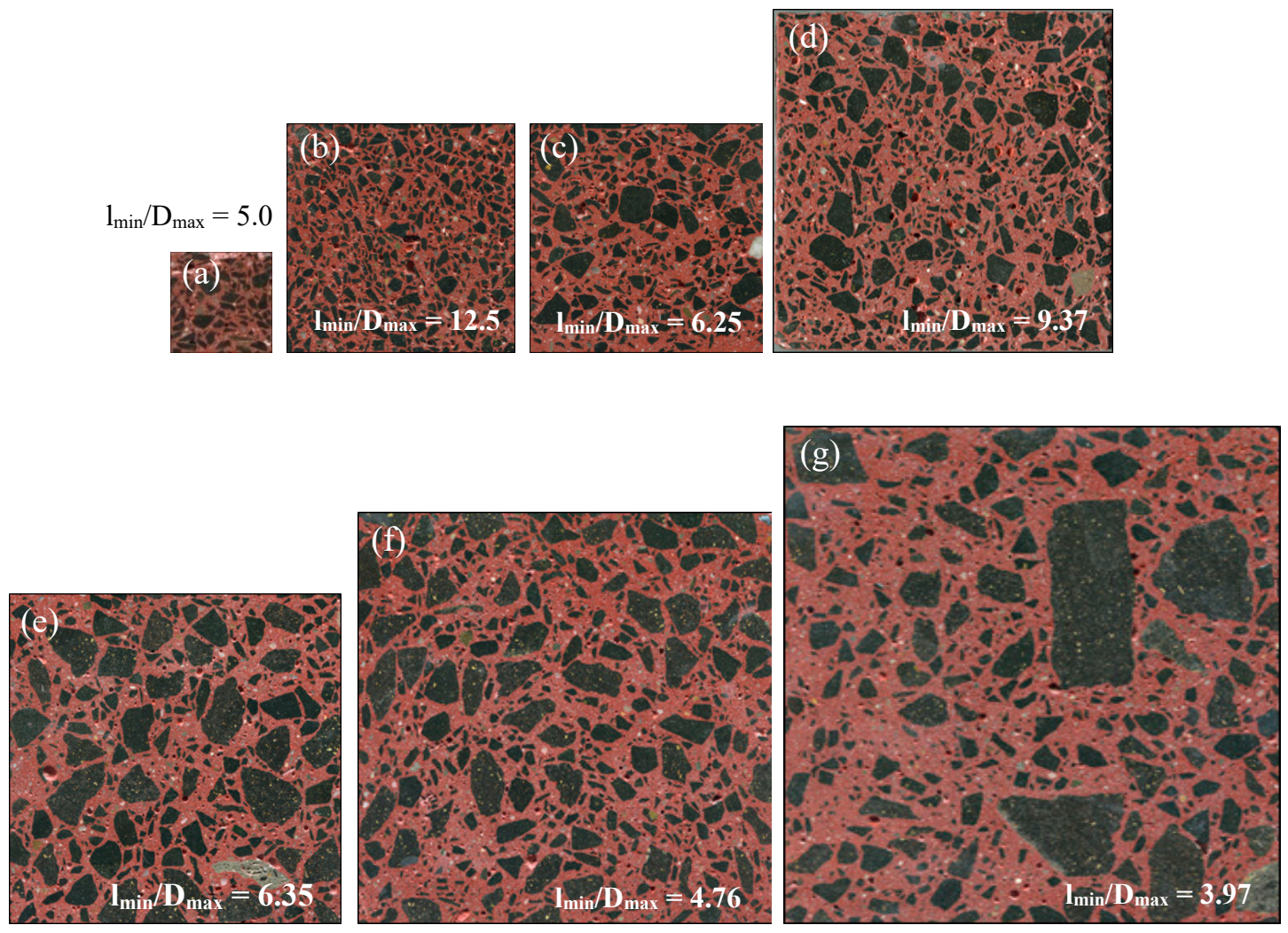

Figure 2. Examples of sample cross-sectional images for which $1_{\min } / \mathrm{D}_{\max }>3.5$ (a) prism $40 \times 40 \times 160 \mathrm{~mm}$, $\mathrm{D}_{\max }=8 \mathrm{~mm}$; (b) cube $100^{3} \mathrm{~mm}, \mathrm{D}_{\max }=8 \mathrm{~mm}$; (c) cube $100^{3} \mathrm{~mm}, \mathrm{D}_{\max }=16 \mathrm{~mm}$; (d) cube $150^{3} \mathrm{~mm}$, $\mathrm{D}_{\max }=16 \mathrm{~mm} ;(\mathbf{e})$ cube $150^{3} \mathrm{~mm}, \mathrm{D}_{\max }=31.5 \mathrm{~mm} ;(\mathbf{f})$ cube $200^{3} \mathrm{~mm}, \mathrm{D}_{\max }=31.5 \mathrm{~mm} ;(\mathrm{g})$ cube $250^{3} \mathrm{~mm}, \mathrm{D}_{\max }=63 \mathrm{~mm}$. 

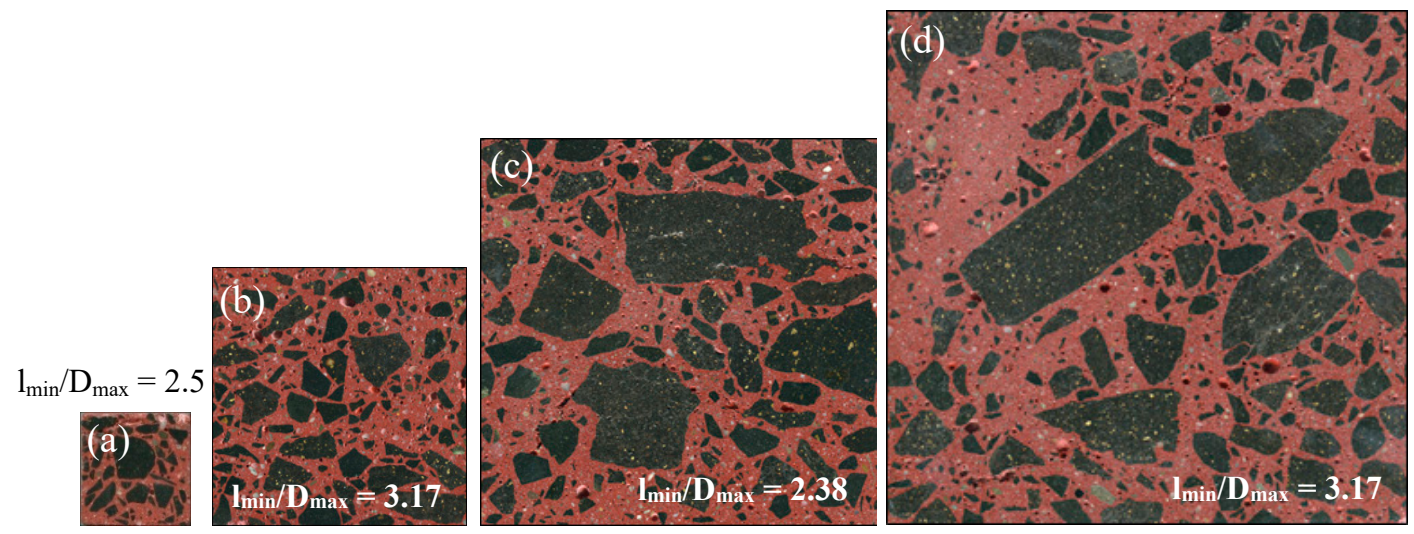

Figure 3. Examples of sample cross-sectional images for which $1_{\min } / \mathrm{D}_{\max }<3.5$ (a) prism $40 \times 40 \times 160 \mathrm{~mm}$, $\mathrm{D}_{\max }=16 \mathrm{~mm}$; (b) cube $100^{3} \mathrm{~mm}, \mathrm{D}_{\max }=31.5 \mathrm{~mm}$; (c) cube $150^{3} \mathrm{~mm}, \mathrm{D}_{\max }=63 \mathrm{~mm}$; (d) cube $200^{3} \mathrm{~mm}$, $\mathrm{D}_{\max }=63 \mathrm{~mm}$.

\subsubsection{Image Analysis}

The analysis of the obtained sample cross-sectional images was performed with the GNU Image Manipulation Program (GIMP 2.10) [22]. It is an open access software for editing photos and other graphic files. This program enables a quantitative evaluation of the area occupied in 2D images by the basic components of hardened concrete, i.e., coarse aggregate with grains from $2 \mathrm{~mm}$ to $\mathrm{D}_{\max }$, sand from 0 to $2 \mathrm{~mm}$ and hardened paste. As sand and paste form a mortar, it was possible to assess the contribution of this component as well.

The content of coarse aggregate (basalt grits $2 / \mathrm{D}_{\max }$ ) and mortar in the sample concrete was determined by drawing the edges around each grain, and then, filling these outlines with black using the "threshold" tool. On the image modified in this manner, the fraction of black (coarse aggregate) and white (mortar) surfaces was read from the colour histogram. An example of the result of this analysis stage is presented in Figure 4.
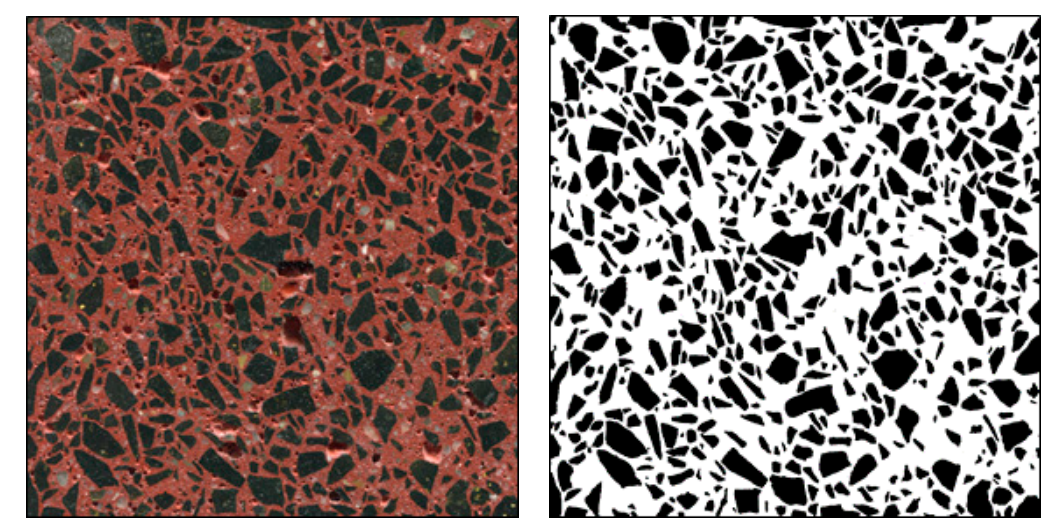

Figure 4. Example of the actual and modified cross-sectional image of a cubic cube sample of $100 \mathrm{~mm}$ side made of concrete with aggregate of $D_{\max }=8 \mathrm{~mm}$ (dimensions of the image $10 \times 100 \mathrm{~mm}$; content of coarse aggregate in concrete $40.2 \%$; content of mortar in concrete $59.8 \%$ ).

Then, the content of sand and cement paste in the mortar was subjected to similar analysis. For this purpose, the largest possible cross-sectional area of the mortar image between the coarse aggregate grains was selected on the cross-sectional image of the sample, then, the edges of the sand grains were outlined and their contours were filled with black colour. An example of this analysis stage is presented in Figure 5. Since the analysed fragments of isolated mortar had a small surface area (from approx. 120 to approx. $250 \mathrm{~mm}^{2}$ ) for each sample, three fragments were analysed, and the following results are mean values. 

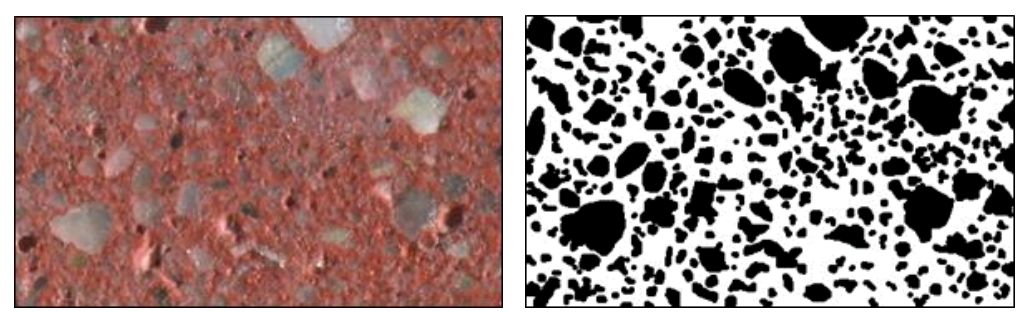

Figure 5. Example of the actual and modified cross-sectional image of a cubic sample of $100 \mathrm{~mm}$ side made of concrete with aggregate of $D_{\max }=8 \mathrm{~mm}$ (dimensions of the image $9.29 \times 15.66 \mathrm{~mm}$; content of sand in mortar $44.5 \%$; content of paste in mortar $55.5 \%$ ).

Furthermore, knowing the content of sand and paste in the mortar and the content of mortar in the concrete, the content of sand and cement paste in the concrete was calculated

\section{Results}

The results of the tests in the form of experimentally determined averaged (from observations on three samples) contents of particular concrete components in particular sample variants are presented in Table 4 and Figure 6. It should be added that the results of the component content assessment for the three samples were homogeneous. In Table 4, in addition to the mean values, the values of the coefficient of variation are given.
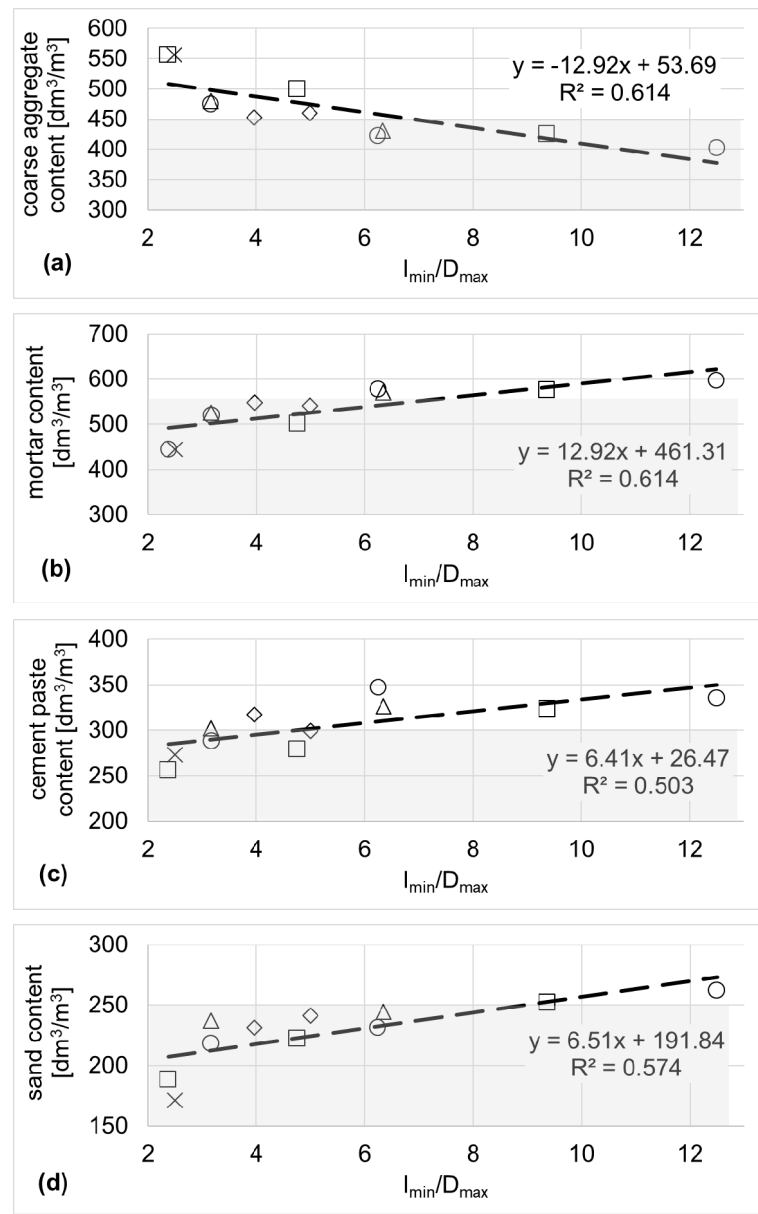

Figure 6. The $1_{\min } / D_{\max }$ ratio and the variability of the experimentally determined absolute content of concrete components in the samples (a) coarse aggregate; (b) mortar; (c) cement paste; (d) sand (according to the concrete mix proportion, the component contents are: coarse aggregate $450 \mathrm{dm}^{3} / \mathrm{m}^{3}$; sand $250 \mathrm{dm}^{3} / \mathrm{m}^{3}$; cement paste $300 \mathrm{dm}^{3} / \mathrm{m}^{3}$; mortar $550 \mathrm{dm}^{3} / \mathrm{m}^{3}$ ). 
Table 4. Experimentally determined contents of concrete components in the analysed samples.

\begin{tabular}{|c|c|c|c|c|c|c|}
\hline \multirow{2}{*}{$\begin{array}{c}\text { Sample } \\
\text { Cross-Section } \\
\text { Dimensions } \\
{[\mathrm{mm}]}\end{array}$} & \multirow{2}{*}{$\begin{array}{l}\text { Maximum } \\
\text { Aggregate } \\
\text { Grain Size } \\
D_{\max }[\mathrm{mm}]\end{array}$} & \multirow[t]{2}{*}{$1_{\min } / D_{\max }$} & \multicolumn{4}{|c|}{$\begin{array}{l}\text { Component Content in the Sample }\left[\mathrm{dm}^{3} / \mathrm{m}^{3}\right] \text { (Mean Values } \\
\left.\left[\mathrm{dm}^{3} / \mathrm{m}^{3}\right] / \text { Coefficient of Variation }[\%]\right)\end{array}$} \\
\hline & & & Coarse Aggregate & Sand & Cement Paste & Mortar \\
\hline $150 \times 150$ & 63 & 2.38 & $556(5.9)$ & $188(5.7)$ & $256(6.2)$ & $444(7.4)$ \\
\hline $40 \times 40$ & 16 & 2.50 & $556(7.6)$ & 171 (7.1) & 273 (7.3) & 444 (9.5) \\
\hline $100 \times 100$ & 31.5 & 3.17 & $475(6.3)$ & 237 (5.9) & $288(5.8)$ & $525(5.7)$ \\
\hline $200 \times 200$ & 63 & 3.17 & $80(8.4)$ & 218 (4.6) & $302(4.8)$ & $520(7.7)$ \\
\hline $250 \times 250$ & 63 & 3.97 & $452(7.7)$ & $231(4.3)$ & $317(4.7)$ & $548(6.3)$ \\
\hline $150 \times 150$ & 31.5 & 4.76 & 499 (7.2) & $222(5.6)$ & $279(5.8)$ & $501(7.2)$ \\
\hline $40 \times 40$ & 8 & 5.00 & $460(6.2)$ & 241 (5.7) & 299 (6.6) & $540(5.3)$ \\
\hline $100 \times 100$ & 16 & 6.25 & $422(8.8)$ & $231(4.5)$ & 347 (4.6) & $578(6.4)$ \\
\hline $200 \times 200$ & 31.5 & 6.35 & $430(6.9)$ & 244 (4.9) & $326(5.0)$ & $570(5.2)$ \\
\hline $150 \times 150$ & 16 & 9.37 & $425(6.8)$ & $252(6.0)$ & $323(6.6)$ & 575 (5.1) \\
\hline $100 \times 100$ & 8 & 12.5 & $403(6.3)$ & $262(5.6)$ & $335(6.7)$ & $597(4.2)$ \\
\hline
\end{tabular}

Figure 7 presents the results in the form of relative differences between the content of concrete components in the samples and their content resulting from the concrete mix proportion. Their values were calculated as a percentage quotient of the absolute difference of content of the component in the sample and the content resulting from the concrete mix proportion $\left[\mathrm{dm}^{3} / \mathrm{m}^{3}\right]$ to the content resulting from the concrete mix proportion $\left[\mathrm{dm}^{3} / \mathrm{m}^{3}\right]$.

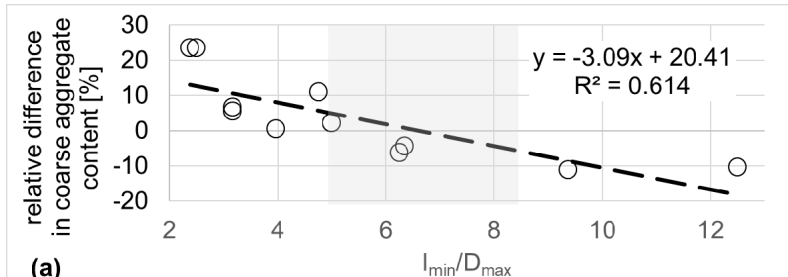

(a)
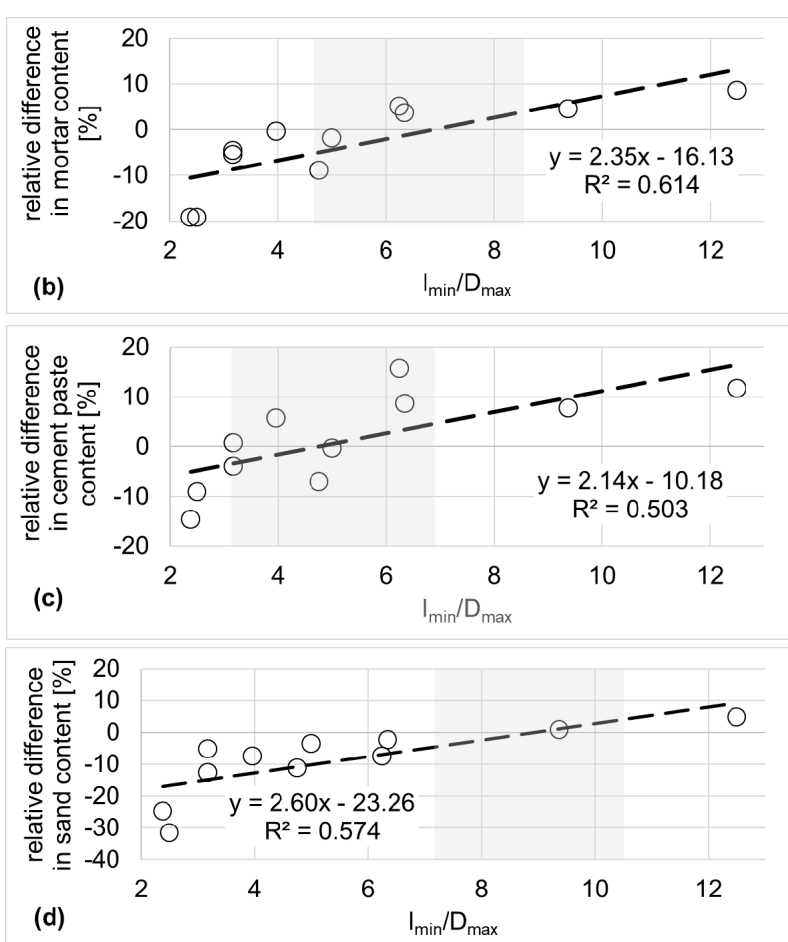

Figure 7. The $1_{\min } / D_{\max }$ ratio and variability of relative differences between the actual content of concrete components in the samples and their content resulting from the concrete formulation (a) coarse aggregate; (b) mortar; (c) cement paste; (d) sand (the grey areas show the range of $1_{\min } / \mathrm{D}_{\max }$ values for which relative differences in the content of components do not exceed $\pm 5 \%$ ). 


\section{Discussion}

\subsection{General Remarks}

Figure 6 shows how experimentally determined volume shares of concrete components in the samples depend on the $1_{\min } / \mathrm{D}_{\max }$ ratio. The contents of all components show a clear tendency to change together with the change of the $1_{\min } / \mathrm{D}_{\max }$ ratio. The absolute differences between their content in concrete samples and that resulting from the concrete formulation are quite significant. In the case of coarse aggregate, its content varies between 403 and $556 \mathrm{dm}^{3} / \mathrm{m}^{3}$, in the case of mortar between 444 and $597 \mathrm{dm}^{3} / \mathrm{m}^{3}$, and in the case of sand and paste between 171 and $262 \mathrm{dm}^{3} / \mathrm{m}^{3}$ and 256 and $335 \mathrm{dm}^{3} / \mathrm{m}^{3}$, respectively.

Even more clearly this differentiation is illustrated by the graphs in Figure 7, showing the relative differences between the component contents of the samples and their contents resulting from the concrete mix formulation. In all cases, the $\mathrm{R}$ linear correlation coefficients of both variables are greater than $0.70\left(R^{2}=0.503\right.$ to 0.614$)$, which indicates the existence of a moderate correlation.

The trends of these relationships have been further analysed. Since it is practically impossible to obtain absolute identity between the concrete composition of the sample and the composition resulting from concrete mix proportion, it has been assumed that if the relative volume differences of the component contents do not exceed $\pm 5 \%$, the concrete composition of the samples may be considered to be conventionally identical with the composition resulting from mix proportions. This somewhat arbitrary assumption is based on the requirement of EN 206:2013 [16] for the accuracy of component dosing during concrete mix production. The accuracy required there is $\pm 3 \%$.

\subsection{Variability of Coarse Aggregate and Mortar Content}

The analysis the regression equations given in Figure 7 shows, in the case of coarse aggregate content in concrete samples, that it differs from the content resulting from the concrete formulation from approx. $+10 \%\left(\right.$ at $\left.l_{\min } / D_{\max }=2.38\right)$, to approx. $-15 \%\left(\right.$ at $\left.l_{\min } / \mathrm{D}_{\max }=12.5\right)$. In the case of mortar content, the difference is the opposite and is -10 and $+15 \%$, respectively. Differences in the content of both these components in the sample, compared to their content resulting from the concrete formulation, not exceeding $\pm 5 \%$, occur at the value of the $1_{\min } / \mathrm{D}_{\max }$ ratio between approximately 5.0 and 8.0 (Figure 7a). In the case of mortar content (Figure 7b), the situation is of course the opposite, as the sum of the volume content of mortar and coarse aggregate is equal to one.

The observed phenomenon can be explained by the fact that with smaller samples in relation to the maximum aggregate grain size (lower $l_{\min } / D_{\max }$ ratio), the presence of even a few of the largest grains causes quite a rapid reduction in mortar content. This situation can be observed in Figure 3, where scans of samples with a relatively low $1_{\min } / \mathrm{D}_{\max }$ ratio $<3.5$ are presented.

\subsection{Variability of Paste and Sand Content}

The variability of cement paste and sand content is related to the variability of the content of the mortar of which they are components. As $1_{\min } / \mathrm{D}_{\max }$ increases, both the paste and sand content grow with similar intensity. For the extreme value of the $1_{\min } / \mathrm{D}_{\max }$ ratio $=2.38$, both sand and cement paste contents are about 10 and 15\% lower than the nominal values, respectively. At the maximum value (12.5), the sand and paste contents show an excess of 10 and $15 \%$ over the nominal contents, respectively.

Differentiation of the cement paste and sand content in the sample, compared to their content resulting from the concrete formulation, not exceeding $\pm 5 \%$, occur in different ranges of the $1_{\min } / \mathrm{D}_{\max }$ ratio. For cement paste, it is in the range from about 3.0 to about 7.0 (Figure 7c) and for sand, from about 7.0 to about 10.0 (Figure $7 d$ ). 


\section{Conclusions}

The results of the presented study give rise to several conclusions and observations.

1. The relationship between sample size and maximum aggregate grain $\left(l_{\min } / D_{\max }\right)$ has a visible effect on the representativeness of the concrete samples as assessed by the similarity of the concrete composition of the sample and the controlled concrete.

2. The differences between the concrete composition in the sample and that resulting from the concrete mix proportion are, particularly at the extremes of the $1_{\min } / \mathrm{D}_{\max }$ ratio, so significant that they should be taken into account when selecting the sample size and interpreting the results of the controlled concrete properties.

3. In light of the results of the tests and analyses, it seems reasonable to recommend the use of samples for which $1_{\min } / \mathrm{D}_{\max }=<5.0 ; 10.0>$.

4. In existing standards, the use of samples that meet the requirement $l_{\min } / \mathrm{D}_{\max } \geq 3.0$ or 3.5 is recommended. In light of the presented test results, this requirement is sufficient for the material strength parameters assessment (compressive and tensile strength) because those properties are not so sensitive to slight variation in concrete composition.

5. The differences between concrete composition in the sample and in controlled concrete, found in this study, may significantly affect the assessment of properties that are sensitive to the concrete composition. Those properties, among others, are water absorption [4], water and gas permeability [5], and thermal properties [6,7].

In conclusion, it should be emphasised that due to the limited number of samples examined, the results presented should be treated as a description of existing trends. Besides, the research presented in this article concerned only one family of concretes with a w/c ratio of 0.50 made of CEM I cement, river sand and basalt grits. Furthermore, these only concerned cubic samples. For these reasons, the presented results are only valid for concretes of similar composition and the samples used in the study. However, it can be assumed that for concretes with different mix compositions or cylindrical samples, similar trends will occur.

Author Contributions: Conceptualization, J.Ś.; methodology, J.Ś. and P.D.; software, P.D.; literature review, J.Ś. and P.D.; investigation, P.D.; writing—original draft preparation, J.Ś.; writing—review and editing, J.Ś., P.D.; funding acquisition, J.Ś. All authors have read and agreed to the published version of the manuscript.

Funding: This research received no external funding.

Conflicts of Interest: The authors declare no conflict of interest.

\section{References}

1. Zheng, J.J.; Li, C.; Zhou, X. Thickness of interfacial transition zone and cement content profiles around aggregates. Mag. Concr. Res. 2005, 57, 397-406. [CrossRef]

2. Stephan, F.F.; McCarthy, P.J. Sampling Options: An Analysis of Survey Procedure; Wiley: New York, NY, USA, 1958.

3. Hill, R. Elastic properties of reinforced solids: Some theoretical principles. J. Mech. Phys. Solids 1963, 11, 357-372. [CrossRef]

4. Tracz, T.; Śliwiński,J. Effect of cement paste content and w/c ratio on concrete water absorption. Cem. Wapno Beton 2012, 17, 131-137.

5. Śliwiński, J.; Tracz, T.; Zdeb, T. Influence of selected parameters of cement concrete composition on its gas permeability, Recent advances in civil engineering: Building materials and building physics, Monograph 479, Cracow University of Technology. Civ. Eng. 2015, 479, 97-118.

6. Kim, K.-H.; Jeon, S.-E.; Kim, J.-K.; Yang, S. An experimental study on thermal conductivity of concrete. Cem. Concr. Res. 2003, 33, 363-371. [CrossRef]

7. Khan, M.I. Factors affecting the thermal properties of concrete and applicability of its prediction models. Build. Environ. 2002, 37, 607-614. [CrossRef] 
8. Gitman, I.; Askes, H.; Sluys, B. Representative volume: Existence and size determination. Eng. Fract. Mech. 2007, 74, 2518-2534. [CrossRef]

9. Stroeven, M.; Askes, H.; Sluys, B. Numerical determination of representative volumes for granular materials. Comput. Methods Appl. Mech. Eng. 2004, 193, 3221-3238. [CrossRef]

10. Yin, Y.; Ren, Q. Studying the representative volume of concrete using the entropy weight-grey correlation model. Mag. Concr. Res. 2018, 70, 757-769. [CrossRef]

11. Ukrainczyk, N.; Koenders, E.A.B. Representative elementary volumes for 3D modeling of mass transport in cementitious materials. Model. Simul. Mater. Sci. Eng. 2014, 22, 35001. [CrossRef]

12. Wu, Q.; Rougelot, T.; Burlion, N.; Bourbon, X. Representative volume element estimation for desorption isotherm of concrete with sliced samples. Cem. Concr. Res. 2015, 76, 1-9. [CrossRef]

13. Yio, M.; Wong, H.S.; Buenfeld, N.R. Representative elementary volume (REV) of cementitious materials from three-dimensional pore structure analysis. Cem. Concr. Res. 2017, 102, 187-202. [CrossRef]

14. Zhang, M.Z.; Ye, G.; van Breugel, K. A numerical-statistical approach to determining the representative elementary volume (REV) of cement paste for measuring diffusivity. Mater. Constr. 2010, 60, 7-20. [CrossRef]

15. Tam, C.; Babu, D.S.; Li, W. EN 206 Conformity Testing for Concrete Strength in Compression. Procedia Eng. 2017, 171, 227-237. [CrossRef]

16. EN 12390-1. Testing Hardened Concrete-Part 1: Shape, Dimensions and others Requirements for Specimens and Moulds; CEN: Brussels, Belgium, 2013.

17. ASTM C 192/C 192M. Standard Practice for Making and Curing Concrete Test Specimens in the Laboratory; ASTM: West Conshohocken, PA, USA, 2000.

18. EN-206. Concrete-Specification, Performance, Production and Conformity; CEN: Brussels, Belgium, 2013.

19. EN-12390-2. Testing Hardened Concrete_Part 2: Making and Curing Specimens for Strength Tests; CEN: Brussels, Belgium, 2019.

20. Mouton, P.R. History of Modern Stereology, IBRO History of Neuroscience. 2005. Available online: http: //www.ibro.info/Pub/Pub_Main_Display.asp?LC_Docs_ID=3159 (accessed on 14 April 2020).

21. Krekule, I.; Kubinova, L.; Karen, P. Evaluation of geometry of three-dimensional objects rendered from serial section and IBM PC implementation of appropriate stereological methods. Acta Vet. Brno 1996, 65, 247-252.

22. GNU Image Manipulation Program (GIMP 2.20). Available online: https://docs.gimp.org (accessed on 11 June 2019).

(C) 2020 by the authors. Licensee MDPI, Basel, Switzerland. This article is an open access article distributed under the terms and conditions of the Creative Commons Attribution (CC BY) license (http://creativecommons.org/licenses/by/4.0/). 